\title{
INDIVIDUALITY, SOCIAL BEHAVIOR, AND REPRODUCTIVE SUCCESS IN YELLOW-BELLIED MARMOTS ${ }^{1}$
}

\author{
Kenneth B. Armitage \\ Department of Systematics and Ecology, The University of Kansas, \\ Lawrence, Kansas 66045 USA
}

\begin{abstract}
Current theory suggests that population dynamics are the consequence of the reproductive strategies of individuals. Individual differences should be expressed in reproductive output, dispersal, social behavior, and recruitment. Mirror-image stimulation (MIS; i.e., exposure of the animal to a large mirror) was used as an independent measure of individuality, which could be distributed continuously or which could be grouped into two or more types. Three axes derived from a factor analysis of behavioral data obtained during MIS accounted for $85 \%$ of the variance among individual marmots. The rank order of 19 adult females on each of the three MIS axes was not correlated with the rank order of lifetime reproductive success measured as number of young weaned, number of yearlings produced, or number of young or yearlings produced per year of residency. This result suggests that individual differences are not continuous.

Each female was assigned to one of three groups according to the MIS axis on which she had her highest factor score. Rankings for the number of female yearlings, number of recruits, and number of 2 -yr-old resident daughters varied significantly among the MIS groups. Mean values of these measures were highest for females in the "sociability" group. Although none of eight measures of lifetime social behavior for 18 females was significantly related to the three MIS groups, several measures of lifetime amicable behavior were correlated with the production and recruitment of female yearlings. Behavior in the field is affected not only by individual behavioral phenotypes, but also by kinship and patterns of space use.

Marmots may have a strategy of phenotypic plasticity. By producing young of varied phenotypes, a female increases the probability that over the long term some of her descendants will survive in varied and unpredictable social and ecological environments.
\end{abstract}

Key words: individuality; kinship; lifetime reproductive success; Marmota flaviventris; phenotypic plasticity; recruitment; social behavior; yellow-bellied marmot.

\section{INTRODUCTION}

Social behavior and differences in individual quality are believed to play prominent roles in population dynamics (Krebs 1978a). Social behavior affects the spacing patterns (Rajska-Jurgiel 1976, Viitala 1977, Dienske 1979), survival (Sadlier 1965, Healey 1967), emigration (Krebs 1970, Myers and Krebs 1971, Braithwaite 1974, Fairbairn 1978, Krebs 1978a), and breeding (Myers and Krebs 1971, Rose 1979) of small mammals.

The major consequence of spacing behaviors is emigration (Wynne-Edwards 1962, Krebs 1978a). Consequently, emigration is widely accepted as a major mechanism limiting the population density of small mammals (Krebs et al. 1973, Armitage and Downhower 1974, Lidicker 1975, Krebs 1978b, Gaines and McClenaghan 1980).

Several authors emphasized the importance of considering population dynamics from the perspective of what happens to individuals. Benefits of emigration to the population (Fairbairn 1978) and socially imposed mortality and the resulting regulation of population size in primates (Dittus 1980) could be considered an outcome of behaviors whose function is to maximize the fitness of individuals. Lømnicki (1982) concluded

Manuscript received 10 June 1985; revised 27 December 1985; accepted 28 January 1986. that population dynamics should be explained as the consequence of the properties of individuals. A major problem is to characterize the nature of individuality in animal populations and determine if individual phenotypes can be used to predict life history traits such as social behavior and reproductive success.

Population dynamics must be explicable in terms of evolutionary theory (e.g., Krebs 1978a, Lømnicki 1978, 1980, 1982). Because evolutionary theory emphasizes that natural selection acts on individual fitness and population dynamics theory stresses individual differences, it follows that population dynamics should be the consequence of the reproductive strategies of individuals. The importance of social behavior in population dynamics theory suggests that social behavior should affect the reproductive strategies of individuals so as to maximize their direct fitness.

An animal's evolutionary fitness is determined by the number of reproductive descendants it produces. An animal's descendants may be either emigrants (individuals vacating their natal population) or recruits (individuals retained in their natal population). However, the relatedness of members of a population and the fate of emigrants are usually unknown. Therefore, fitness usually is estimated from a population parameter other than reproductive descendants, such as shortterm reproductive output.

Social behavior (Armitage 1977) and individuality 
(Svendsen and Armitage 1973) vary among yellowbellied marmots (Marmota flaviventris). Behavioral phenotypes were classified as social, aggressive, or submissive-avoider. Over a $2-y r$ period, submissive females produced few young, social females produced about one-third of the young, and aggressive females produced slightly more than one-half of the young (Svendsen 1974). However, the number of potentially breeding females did not differ among the three groups. The wide difference in reproductive output suggests that submissive animals should be eliminated by their more reproductively successful conspecifics. One possible explanation for their persistence in the population is that a mixed evolutionarily stable strategy exists in which each of the behavioral phenotypes is more fit than the others under certain environmental conditions. Another possible explanation is that short-term reproductive output is an inadequate measure of fitness and that life-time reproductive success does not differ among the three behavioral phenotypes. The purpose of this paper is to relate behavioral phenotypes to social behavior and lifetime reproductive success of female yellow-bellied marmots.

\section{METHODS \\ Basic marmot biology}

Yellow-bellied marmots are large, diurnal, grounddwelling squirrels that occupy a range of middle elevation to alpine environments in the mountains of the western United States (Frase and Hoffmann 1980). Marmot distribution is clumped and corresponds to the patchy distribution of suitable habitat (Svendsen 1974). In our study area in the East River Valley, Colorado (elevation, $2900 \mathrm{~m}$ ), marmots emerge from hibernation in early May and immerge (return belowground) in early September. Copulation occurs during the $2 \mathrm{wk}$ following emergence (Armitage 1965, Nee 1969); young are born about 4 wk later, and are weaned at $\approx 3-4$ wk of age (Armitage 1962). Yearlings, animals $1 \mathrm{yr}$ old in their second summer of life, do not breed and are the major emigrants. Virtually all male yearlings disperse (Armitage 1974, Armitage and Downhower 1974, Downhower and Armitage 1981); $53 \%$ of the female yearlings become residents (Armitage 1984).

Individual marmots may live as isolates, as transients, or as members of social groups (Downhower and Armitage 1971). Social groups range from monogamous pairs to multi-harem colonies. Colonies consist of two social subsystems. Females form a closely related kin group designated a matriline; the male defends a harem consisting of one or more matrilines (Armitage and Johns 1982, Armitage 1984).

\section{Trapping and measurements of social behavior}

Each year since 1962 all resident marmots in four major study sites were trapped and marked with fur dye for visual identification. Numbered tags were affixed to each ear for permanent identification. Details of these procedures and of the study sites were described previously (Armitage 1962, 1974, Svendsen 1974). Behavioral observations, totalling $\approx 250 \mathrm{~h}$ per year, occurred in the morning and late afternoon when animals are most active (Armitage 1962). In most instances, the initiator of the social interaction was determined.

Behaviors were classified as amicable (greeting and allogrooming) or agonistic (avoid, chase, or flee) (Johns and Armitage 1979). Lifetime rates of amicable and agonistic behavior were calculated for each female for her adult years. Each year all social interactions between marmots were recorded. From these data the number of social interactions each adult female had with members of two groups of animals were determined: (1) closely related female kin (related by 0.5 ) and (2) all other females. Interactions with males were not included. The total number of social interactions was divided by the number of females in each group with whom the female could potentially interact. The number of social interactions per female per year was summed over her lifetime and divided by the sum of the number of hours per year each female was observed.

\section{Individuality and reproductive success}

Animals were submitted to mirror-image stimulation (MIS). Each animal was placed in a square arena $92 \times 92 \mathrm{~cm}$ and $31 \mathrm{~cm}$ high. The entrance was through the back; the opposite wall contained a $42 \times 30 \mathrm{~cm}$ glass mirror covered with an opaque partition. Fresh food, mainly dandelion (Taraxacum) or cow parsnip (Heracleum) was placed in the arena. When the marmot was released into the arena, the observer climbed into a blind atop a $1.5 \mathrm{~m}$ tower. After a 15 -min acclimation period, the cover over the mirror was removed by remote control and behaviors recorded for $15 \mathrm{~min}$ (Svendsen and Armitage 1973). The behavioral data were analyzed by factor analysis. A total of 59 adult and yearling marmots formed the data set (Svendsen 1974). Yearlings were included with the adults because no objective basis was found for separating the two age groups. MIS was repeated for eight females, including six for whom lifetime reproductive data were obtained.

Lifetime reproductive success was calculated by summing over the lifetime of each female marmot the total number of young weaned, the number of female young weaned, the total number of yearlings produced, the number of female yearlings produced, and the number of yearlings recruited. A yearling female was considered to be a recruit if she remained in her natal population throughout her second summer of life.

\section{RESULTS}

Factor analysis of the MIS behavioral data produced three factors or axes accounting for $85 \%$ of the variance 


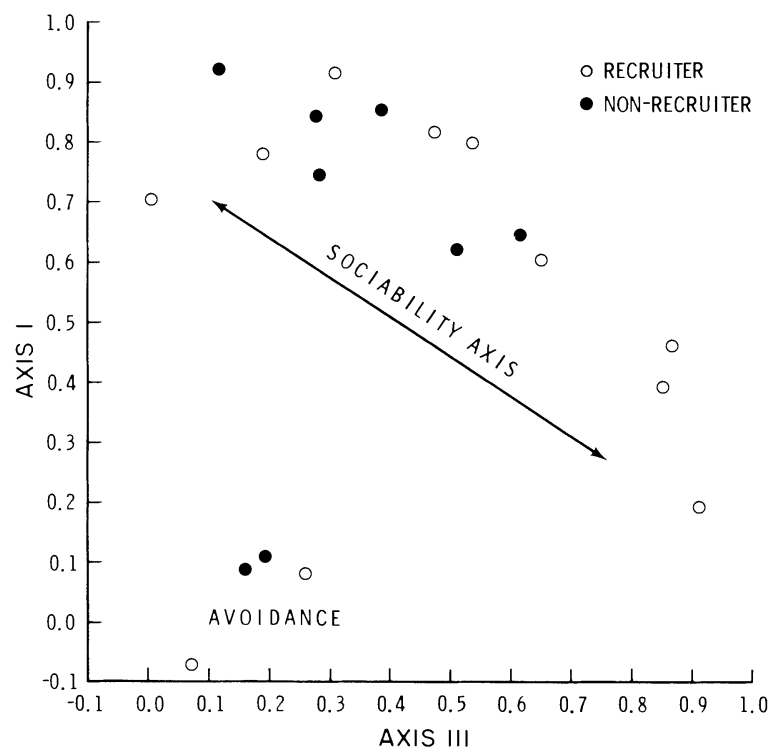

FIG. 1. MIS factor scores on Axis I (approach) plotted against factor scores on Axis III (sociability) for 19 female yellow-bellied marmots. $\bigcirc$, females who recruited daughters; -, females who did not recruit daughters.

(Svendsen 1974). Factor I was represented by marmots who spent most of their time in the front half of the arena oriented to their images. This factor was designated "approach." This group included both aggressive and social animals. Factor II was designated "avoidance" because animals remained in the back of the arena and usually did not approach the mirror, or did so hesitantly. Factor III was characterized by "sociability"; i.e., animals engaged in nose contact, pawing and muzzling of the image, and in arena activity. Factor scores on axis I plotted against factor scores on axis III revealed two groups of animals (Fig. 1). One group of four animals scored low on both axes; these animals scored high on axis II and formed a group of socially submissive animals. The remaining animals lie along a sociability axis; the most sociable are those whose highest factor scores are on axis III.

\section{MIS and reproductive success}

Of the 40 females in the MIS sample of 59 animals, lifetime reproductive success and social behavior were obtained for 19. The factor scores for each female were rank-ordered (high scores to low scores) on each MIS axis. No ranking on any of the three MIS axes was significantly correlated with any ranking of reproductive success measured as total number of young weaned, total number of yearlings produced, number of young weaned per year of residency, or number of yearlings produced per year of residency $\left(r_{s}\right.$ ranged from -0.179 to 0.266 ). One possible explanation for this lack of significant relationships is that individuality does not vary continuously but consists of one or more types with variance around each mean type.
Factor scores of those females for whom MIS was repeated varied among MIS runs. This variation changed the rank order of a female on a MIS axis, but did not change the axis on which she had her highest score. Because each animal was placed into one of three groups according to the axis on which she had her highest factor score (Svendsen and Armitage 1973, Svendsen 1974), no animal changed the group to which it was assgined. Values for each of eight measures of reproductive success were ranked in a separate series. Each rank score for each measure was assigned to the MIS group in which the female associated with that measure was placed. Differences among the sums of the ranks for the three groups were tested by the Kruskal-Wallis one-way analysis of variance by ranks (Siegel 1956:184). Rankings for the number of female yearlings, the number of recruits, and the number of 2 -yr-old resident daughters varied significantly among the MIS groups (Table 1). Although there is no test for a significant difference among means, females scoring high on the "sociability" axis produced more female yearlings, recruited more daughters, and resided with more 2-yr-old daughters than did females in the other two groups.

\section{MIS and social behavior}

Because the major difference among females in lifetime reproductive success may be attributed directly to retaining daughters in the natal area, there may be differences in the social behavior of animals in the three MIS groups. For example, animals scoring high on the "sociability" axis might be expected to engage in more amicable behaviors than females in the other groups. The following measures of lifetime behavior were ranked for 18 female adults: amicable behavior with all females (includes yearlings), agonistic behavior with all females, total social interactions with all females, amicable interactions with related adult females, amicable behavior with unrelated adult females, amicable behavior with yearlings, amicable behavior with female yearlings, and amicable behavior initated with related adult females. Rank scores for each behavior for each female were assigned to the MIS group in which the female was placed. Rank analysis (KruskalWallis one-way ANOVA) revealed no relationship between any of the social behaviors and the three MIS groups (all $P>.1$ ). Because only 6 of the 18 adult females were observed to behave agonistically with female yearlings, agonistic behavior with female yearlings was not included in the analysis.

\section{Social behavior and reproductive success}

The major reason that no relationship occurred between lifetime social behavior and the MIS groups was because of the variability of the group I animals. Rates of social behavior of animals in this group ranked both high and low, whereas ranks of the animals in the other groups tended to be clumped. This variation in social 
TABLE 1. Lifetime reproductive success of 19 female adult yellow-bellied marmots assigned to one of three groups corresponding to the three major axes of the factor analysis of behavior under mirror-image stimulation (MIS).

\begin{tabular}{|c|c|c|c|c|c|}
\hline \multirow[b]{3}{*}{ Measures of reproductive success } & \multicolumn{3}{|c|}{ MIS Groups } & \multirow{2}{*}{\multicolumn{2}{|c|}{ Kruskal-Wallis statistics $\dagger$}} \\
\hline & \multirow{2}{*}{$\begin{array}{l}\text { I (11 \&ᄋ) } \\
\text { Approach }\end{array}$} & \multirow{2}{*}{$\begin{array}{c}\text { II (4 \$?) } \\
\text { Avoidance }\end{array}$} & \multirow{2}{*}{$\begin{array}{c}\text { III (4 ९९) } \\
\text { Sociability }\end{array}$} & & \\
\hline & & & & $H$ & $P$ \\
\hline & \multicolumn{3}{|c|}{ Mean lifetime success* } & & \\
\hline Number of young & 6.3 & 6.8 & 10.0 & 0.7 & $>.3$ \\
\hline Number of yearlings & 2.0 & 5.3 & 3.7 & 5.6 & $.1>P>.05$ \\
\hline Number of young per year of residency & 1.8 & 1.2 & 2.0 & 1.0 & $>.3$ \\
\hline Number of yearlings per year of residency & 0.7 & 1.1 & 0.7 & 0.6 & $>.3$ \\
\hline Number of female young & 2.7 & 1.8 & 6.0 & 4.8 & $.1>P>.05$ \\
\hline Number of female yearlings & 1.0 & 1.5 & 2.5 & 8.8 & $<.02$ \\
\hline Number of recruits & 1.0 & 1.2 & 2.0 & 8.7 & $<.02$ \\
\hline Number of 2 -yr-old resident daughters & 0.6 & 0.8 & 1.8 & 16.2 & $<.001$ \\
\hline
\end{tabular}

* Differences among means cannot be tested for significance.

† For a description of the ranking scheme, see Results: MIS and Reproductive Success.

behavior suggested that reproductive success might be related to behavior observed in the field rather than to MIS groupings. Therefore, lifetime rates for social behaviors were ranked from high to low and compared with rankings of lifetime reproduction (Table 2). There was no relationship between the number of young weaned and social behavior. The production of yearlings and recruitment of female yearlings were significantly correlated with several measures of amicable and total social behavior, but not with agonistic behavior (Table 2).

\section{Discussion}

The failure of MIS to predict rates of social behavior among adult females contrasts sharply with the significant correlation between ranks on MIS axes and rates of social behavior for young (Rains 1979, Armitage 1982) and yearling females (Armitage 1986). At least three factors contributed to this difference. First, the young and yearlings were not reproductive and the yearlings did not associate with adult females. Thus their basic behavioral phenotypes could have been more readily expressed, unaffected by reproductive physiology and, in the case of the yearlings, by subsequent social experiences with adults.

Second, the behavior of marmots in mixed-age populations is strongly affected by the age-sex classes present and by kinship (Armitage and Johns 1982). The sample size of adult females in this study was inadequate to separate out kin effects within the MIS groups. The number of kin available for social interactions varied widely among years and among animals. Amicable behavior with kin (related by 0.5 ) usually exceeded amicable behavior with others (Table 3 ). In those instances when the behavioral ratio of kin/others was close to 1.0 , all others were related by $\leq 0.25$. In all cases, agonistic behavior was much less frequent with kin than with others (Table 3 ). These patterns prevailed across all MIS groups. Some females interacted exclusively with kin, some only with others, and some did not interact at all (Table 4). Some females from all MIS groups interacted amicably only with kin even though others were present; amicable behavior directed toward others was more likely if kin were absent (Table 4). Agonistic behavior by animals from all MIS groups was more likely to be directed exclusively toward others. Some females did not interact either amicably or agonistically in the presence of other females. Most of these socially inactive animals were members of MIS group I (Table 4), but sample size is too small for statistical analysis.

Space use also affects social interactions among females. For example, at North Picnic colony (Armitage 1974), three unrelated adult females and three yearling sisters were resident in 1971. Adult females 755 and 1047 were members of MIS group I. The three yearling females were daughters of 1047 . No social interactions were observed among the adult females nor between the yearling females and any adult female. There was

TABLE 2. Spearman rank correlations between lifetime measures of reproductive success and lifetime rates of social behaviors for 18 adult female yellow-bellied marmots. Al values ranked from high to low.

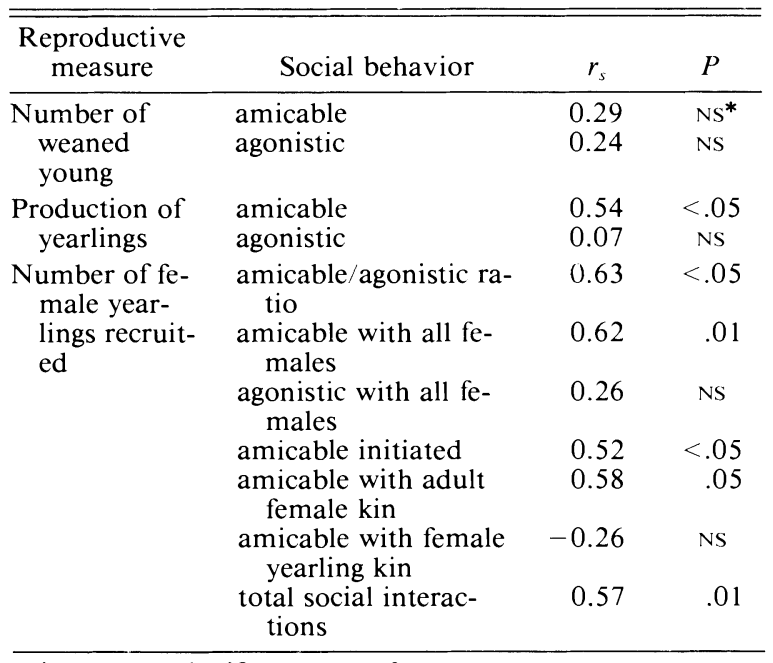

${ }^{*} \mathrm{NS}=$ not significant, $P>.05$. 
TABlE 3. The ratio of amicable and agonistic behaviors (number per animal per hour) among female kin* to those for all "other" females for seven individual adult female yellow-bellied marmots for whom lifetime behavioral data were available.

\begin{tabular}{lrc}
\hline \hline $\begin{array}{c}\text { Amicable behaviors } \\
\text { (among kin/among } \\
\text { others) }\end{array}$ & MIS Group $\dagger$ & $\begin{array}{c}\text { Agonistic } \\
\text { behaviors } \\
\text { (among kin/ } \\
\text { among others) }\end{array}$ \\
\hline $14.9 \quad$ III & $\ldots$ \\
11.7 & II & 0.38 \\
6.9 & II & 0.17 \\
1.6 (grandmother) & III & $\ldots$ \\
1.3 (granddaughters) & III & 0.63 \\
0.8 (nieces) & I & 0.22 \\
$\cdots$ & I & 0.17 \\
\hline
\end{tabular}

* Kin are animals related by 0.5 , "others" include more distant kin and unrelated individuals.

$\dagger$ MIS group is the group in which the female had her highest factor score.

virtually no overlap in space use (Fig. 2). The yearlings used space between the areas occupied by two of the adults. Although the yearlings had no social interactions with their mother, they remained throughout the summer and were classified as recruits.

\section{Individuality and population dynamics}

The two major relationships between individuality and population dynamics of yellow-bellied marmots are the correlation between production and recruitment of yearlings and various measures of amicable behavior (Table 2 ) and the greater reproductive success of females ranking high on the sociability axis (Table 1). The differences in lifetime reproductive success indicate that the differences in annual reproductive output by marmots of different behavioral phenotypes (Svendsen 1974) were not balanced out by length of reproductive life.

The importance of rearing yearlings is supported by demography. The life expectancy of a juvenile is 1.6 $\mathrm{yr}$; that of a yearling is $2.0 \mathrm{yr}$ (Armitage and Downhower 1974). Few 2-yr-old females breed; therefore, fitness is higher if a female produces offspring with a high probability of living to age 3 . Retaining offspring in their natal area into at least their second (yearling) year of life is a behavioral mechanism for continuing reproductive investment beyond weaning in those species of marmots, ground squirrels, and prairie dogs whose age at first breeding is $2 \mathrm{yr}$ or older (Armitage 1981). Presumably amicable behavior influences a female's probability of retaining yearling daughters. Only one female had no amicable interactions with yearling daughters that became recruits; these were the yearlings whose space use did not overlap that of their mother (Fig. 2). Space use by yearling recruits typically is philopatric (Armitage 1984).

Emigration of female yearlings is delayed when they are treated amicably but occurs earlier when they are treated agonistically (Downhower and Armitage 1981). Therefore, successful recruitment should be correlated with amicable behavior with yearling kin. However, amicable behavior between yearling kin and adult females was not significantly correlated with recruitment (Table 2). Four factors may account for the lack of this correlation. First, the critical factor could be the relationship between amicable and agonistic behavior rather than the absolute rates of these behaviors. Amicable/ agonistic ratios varied from 2.0 to 18.9 ; however, no agonistic behavior with yearling females was observed for two-thirds of these adult females. Therefore, recruitment occurs in a cohesive or amicable environment (Table 2).

Second, space use affects the rates of social interactions. Not only may yearlings avoid a potentially agonistic adult (Fig. 2), but in small habitat patches yearlings may spend more time in close proximity to adults and have a higher probability of interacting. The five females occupying restricted areas had the highest rates of amicable behavior with yearling daughters; the number of daughters recruited varied from one to four. The female who lived in a colony with the largest area had the lowest rate of social interactions and recruited four daughters.

Third, the behavioral phenotypes of the yearlings affect adult : yearling behavior. Fourth, the activity of the territorial male may influence the behavior of females and affect the rates of their social interactions.

TABLE 4. The number of female adult yellow-bellied marmots who interacted socially only with closely related kin or with others or who were non-interactive. "Kin" and "others" defined as in Table 3.

\begin{tabular}{|c|c|c|c|c|}
\hline & \multicolumn{2}{|c|}{ Amicable behavior } & \multicolumn{2}{|c|}{ Agonistic behavior } \\
\hline & $\begin{array}{l}\text { No. females } \\
\text { or times }\end{array}$ & $\begin{array}{l}\text { MIS Group } \dagger \\
\text { membership }\end{array}$ & $\begin{array}{l}\text { No. females } \\
\text { or times }\end{array}$ & $\begin{array}{l}\text { MIS Group } \dagger \\
\text { membership }\end{array}$ \\
\hline $\begin{array}{l}\text { Interacted only with kin } \\
\text { Others present* }\end{array}$ & $\begin{array}{l}4 \\
3\end{array}$ & I, I, II, III & $\begin{array}{l}1 \\
1\end{array}$ & II \\
\hline $\begin{array}{l}\text { Interacted only with others } \\
\text { Kin present }\end{array}$ & $\begin{array}{l}3 \\
1\end{array}$ & I, I, II & $\begin{array}{l}6 \\
3\end{array}$ & I, I, I, II, III, III \\
\hline $\begin{array}{l}\text { No interactions } \\
\text { Kin present } \\
\text { Others present* }\end{array}$ & $\begin{array}{l}4 \\
3 \\
4\end{array}$ & I, I, I, I & $\begin{array}{l}6 \\
5 \\
5\end{array}$ & I, I, I, I, II, III \\
\hline
\end{tabular}

* One or more additional adult females were living near the subject female such that social interactions were expected.

† Roman numerals identify groups of females that had similar responses to the sight of themselves in a mirror. 


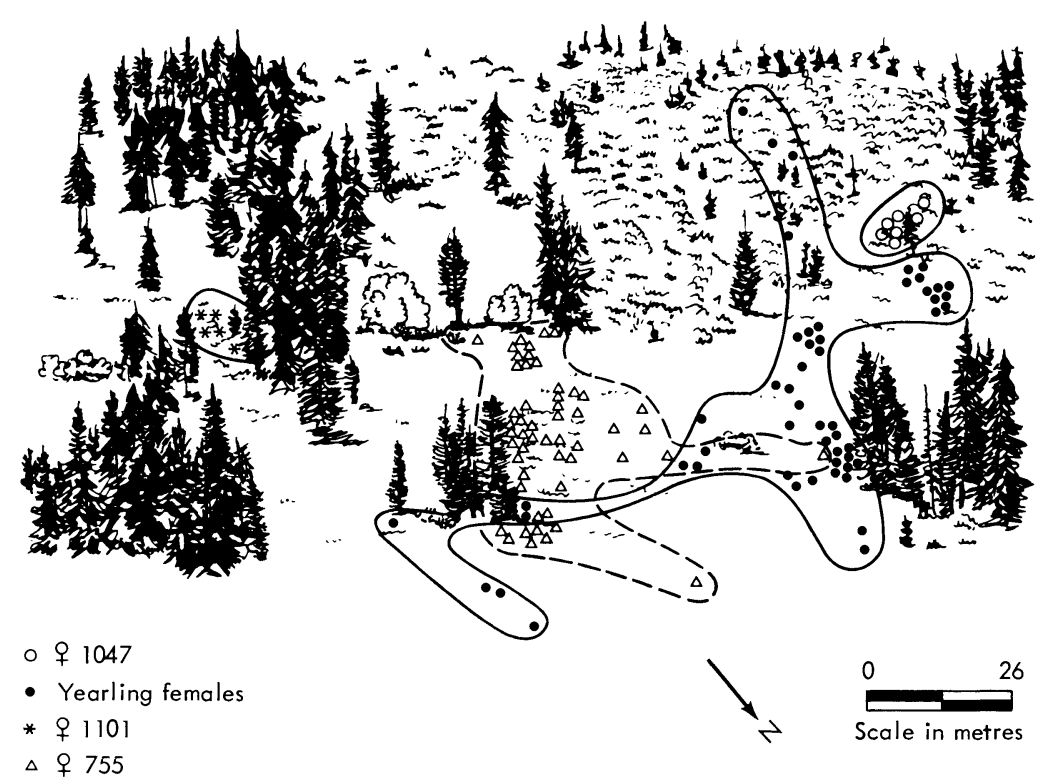

Fig. 2. Space-use domains of three adult females and of three yearling females, daughters of 1047, at North Picnic in 1971. The symbols represent direct census observations; the lines outlining the domains are eye-fitted to assist the reader in evaluating the degree of overlap of domains and include burrows located behind trees.

These relationships have yet to be analyzed for marmots.

\section{Phenotypic plasticity: a model to explain individuality}

A major question is whether the variability in behavior and reproductive success among marmots is adaptive or whether it represents random variation. Wide limits may be tolerated because there is no selection pressure to narrow the limits (Slater 1981). The variation in rates of amicable behavior between resident mothers (recruiters) and recruits may represent randomness. If the behavior with potential recruits is amicable, the frequency of expression of the behavior may be irrelevant. However, the relationship between total amicable behavior and recruitment (Table 2) suggests that natural selection should enhance this behavior. In this study, $47 \%$ of the females failed to recruit. Why, then, is there so much variation and why do so many females fail to recruit?

Two models for the persistence of nonrecruiters in the population are possible. First, fitness may be related to heterozygosity in natural populations (see review by Soulé 1980). Although the selective mechanism for producing an excess of heterozygotes is unknown, the process produces individuals of different fitnesses. If the sociable recruiters should be more heterozygous, the nonrecruiters could represent the less-fit homozygotes (or individuals of lower heterozygosity). Genetic mechanisms would maintain the variability because of the heterozygote advantage.
Alternatively, marmots may have a strategy of phenotypic variability. This strategy is especially appropriate where relevant features of the environment are not predictable from information available to an individual (Slater 1981). Both social and ecological environments of marmots change in space and time (Svendsen 1974, Armitage 1977). A female may increase her fitness by producing diverse offspring phenotypes. Because survival and subsequent reproduction is an exercise in probability (White 1978), diverse phenotypes among a female's offspring may increase the probability of her reproductive success by increasing the probability that some young will survive. Although aggressive females may be less likely to be recruited into a matriline, they may be more successful immigrants. For example, North Picnic colony was populated primarily by successive immigrants (Armitage 1984); all these females were highly aggressive, and in two cases they successfully excluded other potential immigrants.

Recruitment of daughters may be a successful strategy only in large habitat patches where food and burrow resources are adequate to sustain the higher numbers. The longest persisting matriline occurred at Picnic colony, the largest marmot habitat patch in our study area (Armitage 1984). Although matrilines developed in several smaller habitat patches, these matrilines eventually died out and were replaced by immigrants. Although most matrilines eventually go extinct, we have not detected any regularity in their extinction. Therefore, it may be more advantageous for a female to 
distribute her descendants among several habitat patches. This model requires a simple two-strategy system, recruitment and dispersal, that is consistent with game-theoretic models (Davies 1982). An individual female could switch from one strategy to the other depending on her perception of local conditions. This model is too simple to explain the available data. Although some yearling daughters of successful recruiters emigrate, daughters of nonrecruiters are never recruited even when their mother is the only adult female present in their natal area (Armitage 1984).

The individual behavioral phenotypes could be determined by varied social experiences during ontogeny (Bekoff 1977). Several lines of evidence indicate an ontogenetic component in the behavioral phenotypes of marmots. The MIS factor scores of some young change when they become yearlings such that the animal is classified as a different behavioral phenotype (Armitage 1986). The lack of agonistic behavior among young (Nowicki and Armitage 1979, Armitage 1982) and its expression by yearlings and adults, the termination of play bouts among yearlings in midsummer (Jamieson 1985), and the virtual absence of play by adults also suggest an ontogenetic component to the expression of behavioral variability. If behavioral ontogeny can produce an aggressive animal, the same process can also produce a submissive animal.

Adaptive phenotypic variation could arise from intragenotypic strategy-mixing or "adaptive coin-flipping" (Cooper and Kaplan 1982, Kaplan and Cooper 1984). Both genetic and developmental models agree that individual variation can be highly adaptive. Although eventually the various models generating variability should be verified or falsified, elucidation of the role of phenotypic plasticity in determining an animal's inclusive fitness need not await an explanation of the genetic/developmental mechanism.

I propose that phenotypic plasticity is an adaptive strategy of yellow-bellied marmots. Future research should determine the environmental conditions tha contribute to the direct fitness of each behavioral phenotype. We need to know the lifetime reproductive success of a female's offspring (Dunbar 1983). Failure to recruit daughters does not necessarily lower fitness; a female may gain greater direct fitness from one successful son who sires several litters than does a female who recruits a daughter. Therefore, the reproductive success of emigrants must be determined. But the female with the highest fitness may be the one who produces recruits and aggressive immigrants of both sexes. By producing a variety of offspring, she can take advantage of whatever social and ecological environments are available at that particular place and time.

\section{ACKNOWLEDGMENTS}

This research was conducted at the Rocky Mountain Biological Laboratory, Colorado, and supported by grants GB32494, GB-8526, BMS74-21193, DEB78-0727, and DEB81-
21231 from the National Science Foundation. Gerald E. Svendsen performed the MIS analysis. I thank the following for their assistance in the field: Keith Armitage, Dennis Johns, Delbert L. Kilgore, Jr., Orlando A. Schwartz, and Gerald E. Svendsen. Sharon Hagan prepared the figures; Jan Elder and Fran Williams typed the manuscript. This manuscript is based on a paper presented at the Symposium on Origins and Significance of Individual Differences convened at the June 1983 meeting of the Animal Behavior Society.

$$
\text { Literature Cited }
$$

Armitage, K. B. 1962. Social behaviour of a colony of the yellow-bellied marmot (Marmota flaviventris). Animal Behaviour 10:319-331.

$\rightarrow-$. 1965. Vernal behaviour of the yellow-bellied marmot (Marmota flaviventris). Animal Behaviour 13:59-68. $\rightarrow$ 1974. Male behaviour and territoriality in the yellow-bellied marmot. Journal of Zoology (London) 172:233265.

$\rightarrow$ - 1977. Social variety in the yellow-bellied marmot: a population-behavioural system. Animal Behaviour 25: 585-593.

$\rightarrow$ - 1981. Sociality as a life history tactic of ground squirrels. Oecologia (Berlin) 48:36-49.

$\rightarrow$ 1982. Social dynamics of juvenile marmots: role of kinship and individual variability. Behavioral Ecology and Sociobiology 11:33-36.

- 1984. Recruitment in yellow-bellied marmot populations: kinship, philopatry, and individual variability. Pages 377-403 in J. O. Murie and G. R. Michener, editors. Biology of ground-dwelling squirrels. University of $\mathrm{Ne}$ braska Press, Lincoln, Nebraska, USA.

- 1986. Individual differences in the behavior of juvenile yellow-bellied marmots. Behavioral Ecology and Sociobiology, in press.

Armitage, K. B., and J. F. Downhower. 1974. Demography of yellow-bellied marmot populations. Ecology 55:12331245

$\rightarrow$ Armitage, K. B., and D. Johns. 1982. Kinship, reproductive strategies and social dynamics of yellow-bellied marmots. Behavioral Ecology and Sociobiology 11:55-63.

Bekoff, M. 1977. Mammalian dispersal and the ontogeny of individual behavioral phenotypes. American Naturalist 111:715-732.

$\rightarrow$ Braithwaite, R. W. 1974. Behavioural changes associated with the population cycle of Antechinus stuartii (Marsupalia). Australian Journal of Zoology 22:45-62.

Cooper, W. S., and R. H. Kaplan. 1982. Adaptive "coinflipping": a decision-theoretic examination of natural selection for random individual variation. Journal of Theoretical Biology 94:135-151.

Davies, N. B. 1982. Behaviour and competition for scarce resources. Pages 363-380 in King's College Sociobiology Group, editor. Current problems in sociobiology. Cambridge University Press, New York, New York, USA.

$\rightarrow$ Dienske, H. 1979. The importance of social interactions and habitat in competition between Microtus agrestis and M. arvalis. Behaviour 71:1-126.

Dittus, W. P. J. 1980. The social regulation of primate populations: a synthesis. Pages 263-286 in D. G. Lindburg, editor. The macaques: studies in ecology, behavior and evolution. Van Nostrand Reinhold, New York, New York, USA.

Downhower, J. F., and K. B. Armitage. 1971. The yellowbellied marmot and the evolution of polygamy. American Naturalist 105:355-370.

$\rightarrow$ Downhower, J. F., and K. B. Armitage. 1981. Dispersal of yearling yellow-bellied marmots (Marmota flaviventris). Animal Behaviour 29:1064-1069.

Dunbar, R. I. M. 1983. Life history tactics and alternative 
strategies of reproduction. Pages 423-433 in P. Bateson, editor. Mate choice. Cambridge University Press, New York, New York, USA.

$\rightarrow$ Fairbairn, D. J. 1978. Dispersal of deermice, Peromyscus maniculatus: proximal causes and effects on fitness. Oecologia (Berlin) 32:171-193.

$\rightarrow$ Frase, B. A., and R. S. Hoffmann. 1980. Marmota flaviventris. Mammalian Species 135:1-8.

Gaines, M. S., and L. R. McClenaghan, Jr. 1980. Dispersal in small mammals. Annual Review of Ecology and System atics 11:163-196.

Healey, M. C. 1967. Aggression and self-regulation of population size in deermice. Ecology 48:377-392.

Jamieson, S. H. 1985. Sex differences in the play behavior of yearling yellow-bellied marmots. Thesis. University of Kansas, Lawrence, Kansas, USA.

$\rightarrow$ Johns, D., and K. B. Armitage. 1979. Behavioral ecology of alpine yellow-bellied marmots. Behavioral Ecology and Sociobiology 5:133-157.

Kaplan, R. H., and W. S. Cooper. 1984. The evolution of developmental plasticity in reproductive characteristics: an application of the "adaptive coin-flipping" principleAmerican Naturalist 123:393-410.

Krebs, C. J. 1970. Microtus population biology: behavioral changes associated with the population cycle in $M$. ochrogaster and $M$. pennsylvanicus. Ecology 51:34-52.

$\rightarrow \rightarrow-1978 a$. A review of the Chitty Hypothesis of population regulation. Canadian Journal of Zoology 56:24632480 .

- 1978b. Aggression, dispersal, and cyclic changes in populations of small rodents. Pages 49-60 in L. Krames, P. Pliner, and T. Alloway, editors. Aggression, dominance, and individual spacing. Plenum, New York, New York, USA.

Krebs, C. J., M. S. Gaines, B. L. Keller, J. H. Myers, and R. H. Tamarin. 1973. Population cycles in small rodents. Science 179:35-41.

Lidicker, W. Z., Jr. 1975. The role of dispersal in the demography of small mammals. Pages 103-128 in F. B. Golley, K. Petrusewicz, and L. Ryszkowski, editors. Small mammals: their productivity and population dynamics. Cambridge University Press, New York, New York, USA.

Lømnicki, A. 1978. Individual differences between animals and the natural regulation of their numbers. Journal of Animal Ecology 47:461-475.

1980. Group selection and self-regulation in anima populations. Polish Journal of Ecology 28:543-555.

. 1982. Individual heterogeneity and population regulation. Pages 153-167 in King's College Sociobiology
Group, editor. Current problems in sociobiology. Cambridge University Press, New York, New York, USA.

Myers, J. H., and C. J. Krebs. 1971. Genetic, behavioral, and reproductive attributes of dispersing field voles Microtus pennsylvanicus and Microtus ochrogaster. Ecological Monographs 41:53-78.

Nee, J. A. 1969. Reproduction in a population of yellowbellied marmots (Marmota flaviventris). Journal of Mammalogy 50:756-765.

Nowicki, S., and K. B. Armitage. 1979. Behavior of juvenile yellow-bellied marmots: play and social integration. Zeitschrift für Tierpsychologie 51:85-105.

Rains, D. L. 1979. Behavior of juvenile yellow-bellied marmots in two social environments. Thesis. Ohio State University, Columbus, Ohio, USA.

Rajska-Jurgiel, E. 1976. Interactions between individuals of a population of the bank vole, Clethrionomys glareolus (Schreber, 1780). Ekologia Polska 24:3-35.

Rose, R. K. 1979. Levels of wounding in the meadow vole, Microtus pennsylvanicus. Journal of Mammalogy 60:3745.

Sadlier, R. M. F. S. 1965 . The relationship between agonistic behaviour and population changes in the deermouse, Peromyscus maniculatus (Wagner). Journal of Animal Ecology 34:331-352.

Siegel, S. 1956. Nonparametric statistics for the behavioral sciences. McGraw-Hill, New York, New York, USA.

Slater, P. J. B. 1981. Individual differences in animal behavior. Pages 35-49 in P. P. G. Bateson and P. H. Klopfer, editors. Perspectives in ethology. Volume 4. Plenum, New York, New York, USA.

Soulé, M. E. 1980. Thresholds for survival: maintaining fitness and evolutionary potential. Pages 151-169 in M. E. Soulé and B. A. Wilcox, editors. Conservation biology: an evolutionary-ecological perspective. Sinauer Associates, Sunderland, Massachusetts, USA.

Svendsen, G. E. 1974. Behavioral and environmental factors in the spatial distribution and population dynamics of a yellow-bellied marmot population. Ecology 55:760-771.

Svendsen, G. E., and K. B. Armitage. 1973. An application of mirror-image stimulation to field behavioral studies. Ecology 54:623-627.

Viitala, J. 1977. Social organization in cyclic subarctic populations of the voles Clethrionomys rufocanus (Sund.) and Microtus agrestis (L.). Annales Zoologici Fennici 14:53-93.

White, T.C. R. 1978. The importance of a selective shortage of food in animal ecology. Oecologia (Berlin) 33:71-86.

Wynne-Edwards, V. C. 1962. Animal dispersion in relation to social behaviour. Oliver and Boyd, Edinburgh, Scotland. 